City University of New York (CUNY) CUNY Academic Works

\title{
Calibration and Validation of a Regional Climate Model for Pan- Arctic Hydrologic Simulation
}

Helin Wei

lowa State University

William J. Gutowski Jr.

lowa State University

Charles J. Vörösmarty

CUNY City College

Balazs M. Fekete

University of New Hampshire, Durham

\section{How does access to this work benefit you? Let us know!}

More information about this work at: https://academicworks.cuny.edu/asrc_pubs/8

Discover additional works at: https://academicworks.cuny.edu

This work is made publicly available by the City University of New York (CUNY).

Contact: AcademicWorks@cuny.edu 


\title{
Calibration and Validation of a Regional Climate Model for Pan-Arctic Hydrologic Simulation
}

\author{
HELIN WeI* \\ Department of Geological and Atmospheric Sciences, Iowa State University, Ames, Iowa \\ WILLIAM J. GUTOWSKI JR. \\ Department of Geological and Atmospheric Sciences and Department of Agronomy, Iowa State University, Ames, Iowa \\ Charles J. Vorosmarty and Balazs M. FeKete \\ Institute for the Study of Earth, Oceans and Space, and Earth Sciences Department, University of New Hampshire, \\ Durham, New Hampshire
}

(Manuscript received 25 May 2001, in final form 15 March 2002)

\begin{abstract}
A number of polar datasets have recently been released involving in situ measurements, satellite retrievals, and reanalysis output that provide new opportunities to evaluate regional climate in the Arctic. These data have been used to assess a 1-yr pan-Arctic simulation (October 1985-September 1986) performed by a version of the fifth-generation Pennsylvania State University-National Center for Atmospheric Research (PSU-NCAR) Mesoscale Model (MM5) that incorporated the NCAR land surface model (LSM) and a simple thermodynamic sea ice model to investigate interactions between the land surface and atmosphere. The model's standard cloud scheme using relative humidity was replaced by one using simulated cloud liquid water and ice water after a set of short test simulations revealed excessive cloud cover.

Model validation concentrates on factors relevant to the water cycle: atmospheric circulation, temperature, surface radiation fluxes, precipitation, and runoff. The model captures general patterns of atmospheric circulation over land. The rms differences from the Historical Arctic Rawinsonde Archive (HARA) rawinsonde winds at $850 \mathrm{hPa}$ are smaller for the simulation $\left(9.8 \mathrm{~m} \mathrm{~s}^{-1}\right)$ than for the NCEP-NCAR reanalysis $\left(10.5 \mathrm{~m} \mathrm{~s}^{-1}\right)$ that supplies the model's boundary conditions. For continental watersheds, the model simulates well annual average surface air temperature (bias $<2^{\circ} \mathrm{C}$ ) and precipitation (bias $<0.5 \mathrm{~mm} \mathrm{day}^{-1}$ ). However, the model has a summer dry bias with monthly precipitation error occasionally exceeding $1 \mathrm{~mm}$ day ${ }^{-1}$. The model simulates the approximate magnitude of spring runoff surge, but annual runoff is less than observed (18\%-48\% less among the continental watersheds). Analysis of precipitation and surface air temperature errors indicates that further improvements in both evapotranspiration and precipitation are needed to simulate well the full annual water cycle.
\end{abstract}

\section{Introduction}

Watersheds surrounding the Arctic Ocean are significant contributors to the hydrologic cycle of the Northern Hemisphere's polar region. Taken together, Arctic river basins encompass $17 \times 10^{6} \mathrm{~km}^{2}$ of landmass, and this pan-Arctic drainage system is part of a tightly linked land-ocean system. The land-based area is $20 \%$ larger than the Arctic Ocean to which it empties, a unique condition among all other land-ocean basins (Voros-

\footnotetext{
* Current affiliation: Byrd Polar Research Center, Ohio State University, Columbus, Ohio.
}

Corresponding author address: Dr. William J. Gutowski, Atmospheric Science, 3010 Agronomy Building, Ames, IA 50011.

E-mail: gutowski@iastate.edu marty et al. 2000a). The land-based hydrologic cycle for this pan-Arctic region and its resultant freshwater discharges to the Arctic Ocean may play an important role in determining the Arctic Ocean's thermal and salinity gradients, thereby affecting sea ice, regional ocean-circulation dynamics, and the formation of Atlantic deep water. Multiyear feedback links may exist that couple river discharge, ocean ice and temperature distributions, and the region's atmospheric circulation (e.g., Mysak 1995). The river flow also delivers to the Arctic Ocean dissolved constituents and sediments that could affect oceanic primary production and $\mathrm{CO}_{2}$ uptake.

General circulation model (GCM) simulations show that the pan-Arctic region may be highly sensitive to global warming, with relatively large temperature increases, especially in winter (e.g., Kattenberg et al. 
1995). The impacts of potential climatic change in this high latitude region are far-reaching and encompass a wide array of earth system processes including the alteration of hydrologically important variables such as sea ice, precipitation, and cloud cover (Mitchell et al. 1990), as well as contributing processes such as permafrost dynamics (e.g., Anisimov and Nelson 1996; Anisimov et al. 1997) and ecosystem productivity (e.g., Oechel et al. 2000).

The complex interactions and feedbacks occurring include many processes that are still poorly understood and thus pose a challenge for numerical models. As a consequence, GCMs have produced large biases relative to available Arctic observations in surface temperature and pressure fields (Walsh and Crane 1992), clouds and radiation (Curry and Ebert 1992), precipitation (Walsh et al. 1998), and boundary layer processes (Battisti et al. 1992). Substantial intermodel discrepancies also exist. Tao et al. (1996) found that zonal and seasonal average surface air temperatures in GCM simulations for the Atmospheric Model Intercomparison Project (AMIP) spread by $5^{\circ} \mathrm{C}$ or more about corresponding observed Arctic temperatures. Zonal average AMIP Arctic output also differed substantially from observations in annual average precipitation and seasonal average sea level pressure and cloudiness (Chen et al. 1995).

Several factors may produce these biases and discrepancies, with many due to characteristic polar conditions such as weak insolation, extreme cold and accompanying low atmospheric moisture content, lowertroposphere inversions, ice clouds and mixed-phase clouds (e.g., Pinto et al. 1999). This combination of conditions indicates that some Arctic-specific physics parameterizations may be required (Pinto et al. 1999). However the pan-Arctic region, particularly the Arctic Ocean, has been relatively poorly observed in the past, which has inhibited understanding polar climate processes and their modeling.

In the past decade, much progress has been made on in situ measurements and data analysis for the pan-Arctic. The Surface Heat Budget of the Arctic (SHEBA) field program, the Atmospheric Radiation Measurement (ARM) program, the First ISCCP Regional Experiment (FIRE) Arctic Clouds Experiment have been conducted simultaneously over the Arctic Ocean (Randall et al. 1998). By assembling existing datasets and using new in situ measurements along with other sources like remote sensing, scientists have produced many long-term datasets of high quality to evaluate Arctic model simulations. These include the Historical Arctic Rawinsonde Archive (HARA; Kahl et al. 1992), Arctic Ocean radiative fluxes estimated from the International Satellite Cloud Climatology Project-C2 (ISCCP-C2) dataset (Rossow et al. 1988, 1996), Arctic 2-m air temperatures from a variety of land and ocean sites (Rigor et al. 2000), 3-hourly and monthly fluxes from the Polar Radiation Flux project (Key et al. 1999), and Television and Infrared Observation Satellite (TIROS) Operational Vertical Sounder (TOVS) Polar Pathfinder (Path-P) daily Arctic gridded atmospheric parameters (National Snow and Ice Data Center 1999). These datasets provide a variety of useful perspectives for understanding polar climate mechanisms and improving climate model simulations.

Surface processes in the pan-Arctic, particularly hydrological components such as snow and sea ice, have strong interactions with the atmosphere. However, typical vertical and horizontal resolutions of GCMs have been shown to be too coarse to give acceptable descriptions of orography, land-sea contrast, and the cloudy boundary layer, thus undermining accurate simulation of surface-atmosphere interaction. Curry et al. (1996) also have noted that another important contributor to polar region bias in GCMs is that all perform physics computations on equal-angle map projections rather than equal-area maps. Grid boxes thus shrink toward polar latitudes, casting doubt on the validity of subgrid physics parameterizations, which may be very scaledependent. Gridpoint GCMs also apply filters at high latitudes to avoid computational instability (e.g., Arakawa and Lamb 1979). Spectral GCMs must invoke moisture adjustments to eliminate negative moisture in high latitudes that occurs when truncated spectral series attempt to represent moisture fields that decrease rapidly with latitude (e.g., Williamson and Rasch 1994). Both of these nonphysical procedures can have undesirable effects on model results (Curry et al. 1996).

To overcome deficiencies in resolution, many scientists have worked on developing regional climate models (RCM) for Arctic applications (e.g., Walsh et al. 1993; Lynch et al. 1995; Dethloff et al. 1996; Jurrens 1999). These models have been used to study a variety of relevant processes such as the influence of ocean circulation (Bailey et al. 1997), specification of tundra vegetation characteristics (Lynch et al. 1999), permafrost simulation (Christensen and Kuhry 2000), carbon cycle modeling (Wu and Lynch 2000), and atmospheric boundary layer parameterization (Dethloff et al. 2001). Typically, evaluations of simulations by these models have used comparisons with gridded analyses, which are themselves partially products of forecast models, or observations from a limited number of sites.

In this study, we use the fifth-generation Pennsylvania State University-National Center for Atmospheric Research (PSU-NCAR) Mesoscale Model (MM5; Grell et al. 1994) to perform simulations up to 1-yr long that use the U.S. National Centers for Environmental Prediction (NCEP)-NCAR reanalysis (Kalnay et al. 1996) for initial and lateral boundary conditions. We use the observations-based datasets listed earlier and others to evaluate this model's behavior from a variety of perspectives. Using all of this rich resource of pan-Arctic data is important for it limits ad hoc calibrations one might perform simply to match one or two fields.

Random error influences the model's simulation ac- 
TABLE 1. Datasets summary.

\begin{tabular}{lll}
\hline \hline \multicolumn{1}{c}{ Dataset } & \multicolumn{1}{c}{ Reference } \\
\hline TOVS Pathfinder & Schweiger et al. (1999) & \multicolumn{1}{c}{ Source } \\
2-m air temperature & Rigor et al. (2000) & http://nsidc.org/NSIDC/CATALOG/ \\
Polar radiation flux & Key et al. (1999) & http://stratus.ssec.wisc.edu \\
HARA & Kahl et al. (1992) & http://nsidc.org/NSIDC/CATALOG/ \\
CMAP & Xie and Arkin (1997) & ftp://ftp.ncep.noaa.gov:pub/precip/cmap/monthly \\
Composite runoff & Fekete et al. (1999) & http://www.grdc.sr.unh.edu/ \\
NCEP-NCAR reanalysis & Kalnay et al. (1996) & \\
\hline
\end{tabular}

curacy, but spatial averaging can reduce the magnitude of random error, implying that larger regions may be simulated more accurately than smaller ones. We quantify the scale-dependence of error for some of the surface fields that affect hydrologic cycle simulation, thereby inferring sizes of river basins for which the model gives acceptable simulation.

The paper is organized as follows. In section 2, we describe the datasets used to evaluate our simulations. In section 3 , we describe the model and simulation design. In section 4, we illustrate the model's sensitivity to cloud cover simulation and present cloud-scheme tests used to calibrate the model. Section 5 shows the calibrated model's behavior versus observations, with an assessment of the scale-dependence of model errors. In section 6, we present our main conclusions.

\section{Observational data}

As discussed above, several high-quality observational datasets exist for pan-Arctic fields. The datasets described below give us a fairly broad depiction of the model's capabilities and also collectively suggest avenues for model improvement. Datasets used here are summarized in Table 1.

\section{a. TOVS Pathfinder daily Arctic gridded atmospheric parameters}

The TIROS-N Operational Vertical Sounder Polar Pathfinder (Path-P) dataset contains gridded, daily Arctic atmospheric data based on satellite retrievals. The TOVS Path-P dataset covers areas poleward of $60^{\circ} \mathrm{N}$ for July 1979-December 1988 at $100-\mathrm{km}$ resolution. TOVS Path-P retrievals used a physical-statistical retrieval method by Chedin et al. (1985), updated by Francis (1994) for application in snow- and ice-covered areas. Schweiger et al. (1999) validated retrievals through comparisons with surface observations from polar-drifting meteorological stations. TOVS Path-P variables include several fields from which we use precipitable water and boundary layer stratification.

\section{b. Arctic 2-m air temperatures}

This dataset is derived from a new, gridded, 6-hourly, 2-m air temperature dataset for Arctic land and ocean prepared by the Polar Exchange at the Sea Surface (POLES) project (Rigor et al. 2000). Gridded air temperatures are computed using optimal interpolation of observations from drifting buoys, manned Soviet North Pole drifting ice stations, coastal land weather stations, ship reports, and more than 1600 meteorological land stations in the Arctic for the period 1979-97. Errors in this data are approximately $0.1{ }^{\circ} \mathrm{C}$ for coastal stations and $2.0^{\circ} \mathrm{C}$ for the drifting buoys. The resulting gridded fields of 2-m air temperatures show a positive bias of $0.3^{\circ}-1.3^{\circ} \mathrm{C}$ compared to data from Soviet drifting stations (Overland et al. 1997).

\section{c. Polar radiation flux}

The Polar Radiation Flux Project (Key et al. 1999) provides 3-hourly flux coverage for Arctic and Antarctic regions above $57.5^{\circ}$ latitude, for several years (currently, 1985-93). Flux generation uses 3-hourly cloud, atmosphere, and surface data in the ISCCP D1 dataset (Rossow et al. 1988, 1996), supplemented by more accurate atmospheric temperature and water vapor profiles from the TOVS Pathfinder Path-P dataset, when available. The fluxes are generated using a neural net trained on a small subset of the available ISCCP data for which the dataset developers also computed fluxes using a detailed radiative transfer model. For the period of our simulation, the dataset may contain sampling bias as only one polar satellite was available. This dataset includes 11 types of fluxes at the surface and top of the atmosphere. We report here comparisons of model output with surface shortwave downwelling flux and net surface total radiative flux using monthly datasets derived from 3-hourly data (Table 1 ).

\section{d. Historical Arctic Rawinsonde Archive}

The Historical Arctic Rawinsonde Archive (Kahl et al. 1992) contains millions of rawinsonde ascents from all Arctic land stations poleward of $65^{\circ} \mathrm{N}$, from their respective beginnings of record (late 1940s to late 1950s) through mid-1996. Each sounding typically gives 20-40 levels of temperature, pressure, humidity, and wind observations. For most of the period, there are roughly 80 stations with relatively uniform coverage over the Arctic landmass except for a gap in the Greenland interior. 


\section{e. Climate Prediction Center (CPC) Merged Analysis of Precipitation (CMAP)}

This global, monthly, gridded precipitation dataset (Xie and Arkin 1997) is constructed on a $2.5^{\circ}$ latitudelongitude grid for the period 1979-95 by merging gauge observations, estimates from a variety of satellite observations, and, in one version, the NCEP-NCAR reanalysis. The merged dataset has better quality than its individual sources. We use a version that excludes the reanalysis precipitation, thus avoiding errors of the reanalysis forecast model such as "spectral snow" (Ebisuzaki et al. 1997). The CMAP dataset also gives an estimate of error. For the land portion of our domain during our simulation period, most points have an estimated error less than $45 \%$, but over one-third have error greater than this, and the average error among all land points used here is roughly $40 \%$.

\section{f. University of New Hampshire-Global Runoff Data Centre (UNH-GRDC) Composite Runoff Fields V1.0}

The University of New Hampshire and the Global Runoff Data Centre have produced a dataset that combines observed river discharges with output from a climate-driven water balance model to develop composite runoff fields that are consistent with the observed discharges (Fekete et al. 1999). Such combined runoff fields preserve the accuracy of the discharge measurements as well as the spatial and temporal distribution of simulated runoff, thereby providing a self-consistent estimate of terrestrial runoff over large domains. The method relies on discharge-gauging station records from the WMO Global Runoff Data Centre (Koblenz, Germany) and simulated runoff, with both datasets geographically referenced to a simulated river network at $30^{\prime}$ (lat $\times$ lon) resolution (Vorosmarty et al. 2000a,b). The resulting gridded runoff fields capture the inherent spatial variability of runoff, but at the same time are mass conserving.

\section{g. NCEP-NCAR reanalysis}

The NCEP-NCAR reanalysis (hereafter NNR) combines observations and 6-h forecasts to produce a gridded dataset of several atmospheric values (Kalnay et al. 1996). This dataset was used to produce initial and lateral boundary conditions for the simulations. We also use it here as part of our evaluation of the MM5 circulation fields, but only in the model domain inside the zone where the model ingests lateral boundary conditions. In the Arctic, the analysis has a limited database of observational data, especially away from the surface. Thus, while the reanalysis is constrained by observations, its output in the Arctic will be influenced by the climatology of its forecast model, which may depart from the actual Arctic climate. Developers of the NNR rate its water vapor fields as less accurate than wind and temperature fields (Kalnay et al. 1996). We thus compare our model's output primarily with the NNR circulation fields.

\section{Model and experimental design}

The MM5 model (Grell et al. 1994) has a terrainfollowing vertical coordinate, $\sigma=\left(p-p_{\text {top }}\right) /\left(p_{s}-p_{\text {top }}\right)$, where $p$ is pressure, $p_{\text {top }}$ is the specified model top pressure, and $p_{s}$ is the prognostic surface pressure. In our simulations, it uses $23 \sigma$ levels with the model top at $100 \mathrm{hPa}$. In order to resolve the planetary boundary layer and lower troposphere reasonably well, nine levels are assigned in the range $\sigma=[0.7,1.0]$. The model physics include the Grell cumulus convective scheme (Grell et al. 1991; Grell 1993), a revised version of Blackadar's planetary boundary layer model (Zhang and Anthes 1982), and an explicit treatment of cloud water, rainwater, snow, and ice (Dudhia 1989) for resolved precipitation physics.

We use the NCAR Community Climate Model 2 (CCM2) radiative transfer package to describe radiative effects of ozone, water vapor, carbon dioxide, oxygen, and clouds (Briegleb 1992). The package uses relative humidity to diagnose cloud fraction for the radiation calculation. However, we show later that this scheme produces too much cloud, and we have adopted instead a cloud fraction scheme based on the cloud liquid and ice water produced by the model's explicit moisture scheme.

We incorporated Bonan's (1996) land surface model (LSM) version 1.0 to simulate relevant land processes. LSM is a one-dimensional model of energy, momentum, water, and carbon dioxide exchange between the atmosphere and land. It includes ecological differences between vegetation types and hydraulic and thermal differences between soil types. Vegetation effects are included through 12 specified plant types that differ in leaf and stem areas, root profile, height, leaf dimension, optical properties, stomatal physiology, roughness length, displacement height, and biomass. These plant types are combined to form 28 different vegetated surfaces, and multiple surface types can exist within a grid cell. LSM includes soil effects by allowing thermal, hydraulic, and radiative properties that vary with soil texture. Land surface properties in these simulations are translated from MM5's standard global datasets of surface properties. An initial run with the calibrated model using the standard LSM produced very little runoff, even during spring snowmelt, because the model did not change maximum allowable infiltration when soil froze, so all melt water tended to seep into the frozen soil. We modified LSM to prohibit infiltration when temperature anywhere in the upper $30 \mathrm{~cm}$ of a grid box's soil column was below freezing.

The model uses a simple thermodynamic sea ice model similar to the HIRHAM model (Rinke et al. 1999; 
Dethloff et al. 2001) to calculate the sea ice skin temperature. The skin temperature $T_{\text {skin }}$ is predicted using the surface energy equation,

$$
C_{g} \frac{\partial T_{\text {skin }}}{\partial t}=R_{n}-H_{s}-H_{l}+Q_{f}
$$

where $C_{g}$ is the thermal heat capacity of the ice slab per unit area, $R_{n}$ is the net radiation, $H_{s}$ is the sensible heat flux, $H_{l}$ is latent heat flux, and $Q_{f}$ is a constant oceanic heat flux $\left(=2 \mathrm{~W} \mathrm{~m}^{-2}\right)$. When present in a grid box, ice cover is assumed to be $100 \%$, with a constant thickness of $2 \mathrm{~m}$. The ocean temperature below sea ice is specified to $271.2 \mathrm{~K}$.

The model domain is a polar stereographic projection of a $51 \times 91$ array of grid points with $120-\mathrm{km}$ grid spacing, centered over the Arctic Ocean and oriented to cover the North American and Eurasian landmasses of the pan-Arctic (Fig. 1). For this domain, the model's lateral buffer zone that introduces large-scale forcing into the interior is located in areas where there are relatively high-quality observational data ingested into the reanalysis. Thus, we avoid placing a boundary across the Arctic Ocean, where there are fewer high-quality observations of the atmosphere. We performed some 1month tests with $60-\mathrm{km}$ horizontal resolution and found little difference in circulation, precipitation, and temperature fields for seasonal averages on continental watershed scales. Differences do exist on smaller spatial scales that are generally small departures from the 120$\mathrm{km}$ grid's climatology, though these differences could be significant for much smaller watersheds than the continental-scale focus here (Fig. 1).

Four subregions have been selected for regional analysis: the Asian Arctic Watershed (AAW), the North American Arctic Watershed (NAAW), the European Arctic Watershed (EAA), and the Central Arctic Ocean (CAO). Major basins in the AAW include the Ob, Lena, Yenesei, and Kolyma basins, which collectively cover $67 \%$ of the AAW. Major basins in the NAAW include the MacKenzie, Nelson, Churchill, and Baker basins, which collectively cover almost half of the NAW. Spatial average values for the three Arctic watersheds include only land points outside the 10-gridpoint buffer zone where the model ingested lateral boundary conditions. When comparing model output with observations averaged over these watersheds, we first interpolate observational data to the model grid, using bilinear interpolation, and then average.

Initial and lateral boundary conditions, including sea surface temperature (SST) and sea ice distribution, were interpolated from the NNR. The reanalysis used a global spectral model with T62 $\left(\sim 1.9^{\circ}\right)$ horizontal resolution and 28 vertical levels. The reanalysis vertical structure thus differs from our model's structure and extends farther from the surface. The NNR obtained its sea ice for our simulation period from satellite microwave retrievals processed by the European Centre for Medium-

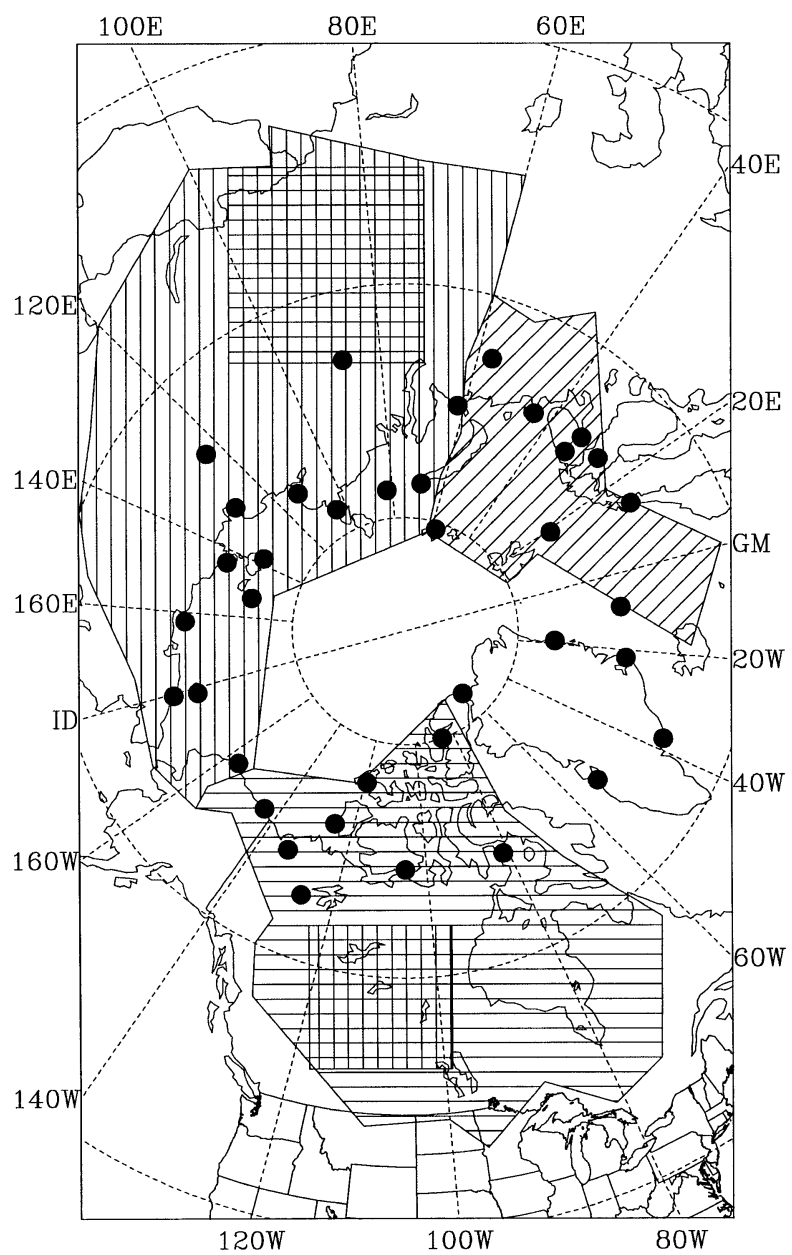

FIG. 1. Model domain and subregions for analysis [vertical hatching: Asian Arctic Watershed (AAW); horizontal hatching: North American Arctic Watershed (NAAW); slanted hatching: European Arctic Watershed (EAW); north of $70^{\circ} \mathrm{N}$ : Central Arctic Ocean (CAO)]. Solid symbols mark locations of HARA soundings used for comparison with model output. Two areas for the analysis of scaledependent errors are outlined by the frames with grid lines.

Range Weather Forecasts (ECMWF). Atmospheric boundary conditions, SST, and sea ice distribution were updated every $12 \mathrm{~h}$.

Our primary target was a $1-y r$ simulation from 0000 UTC 1 October 1985 to 0000 UTC 1 October 1986. As discussed in greater detail later, this was a year when observed discharge from the major pan-Arctic rivers was about the same as long-term climatology. Prior to our October 1985 start, we ran a 2-month simulation repeating September 1985 to account for model spinup of soil moisture and temperature and to obtain more accurate initial fields for the land surface model. Analysis of the September 1985 simulations indicated that no substantial additional spinup would occur were we to continue repeating this month. Spinup and simulation through the end of December used the original LSM. The modified LSM was used from January onward to encompass the period of strong spring snowmelt. 
TABLE 2. Cloud schemes tested.

\begin{tabular}{cl}
\hline \hline Scheme & \multicolumn{1}{c}{ Algorithm } \\
\hline 1 & RH threshold $=75 \%$ (standard MM5) \\
2 & RH threshold $=90 \%$ \\
3 & If $C_{L}>0.01 \mathrm{~kg} \mathrm{~m}^{-3}$ or $C_{I}>0.005 \mathrm{~kg} \mathrm{~m}^{-3}$, then the layer's cloud fraction is 0.75. \\
4 & If $C_{L}>0.01 \mathrm{~kg} \mathrm{~m}^{-3}$ or $C_{I}>0.005 \mathrm{~kg} \mathrm{~m}^{-3}$, then the layer's cloud fraction is 0.90. \\
\hline
\end{tabular}

\section{Cloud calibration}

When applying the model to the Arctic, we found that simulated results, especially for precipitation, were quite sensitive to simulated cloud cover. Antarctic simulations using MM5 (Hines et al. 1995, 1997a,b) suggest that the standard version of MM5 poorly represents cloud cover and radiative fields over extensive ice sheets, particularly during winter months. In this study, we have tested several different cloud fraction schemes, and chosen the best one for the 1-yr simulation. We performed several simulations for the months October 1985 and July 1986 in which we focused on sensitivity of precipitation to the cloud scheme. The standard cloud diagnosis in MM5's CCM2 radiation package computes cloud cover fraction as a function of relative humidity above $75 \%$ (Table 2). However, this scheme produced excessive cloud cover compared to climatology (Serreze et al. 1997; not shown) and too little precipitation (Fig. 2 ). Raising the threshold to $98 \%$ gave little improvement. Cloud cover was greatest in the atmospheric boundary layer.

Guided by previous studies (e.g., Lynch et al. 1995), we used the model-generated cloud liquid water $\left(C_{L}\right)$ and cloud ice water $\left(C_{I}\right)$ to determine cloud fraction. The magnitude of simulated $C_{I}$ in the Arctic is of the same order as $C_{L}$, so using both was considered necessary. In this approach, the model assigns a prespecified cloud fraction to any model layer in which $C_{L}$ or $C_{I}$ exceeds thresholds assigned to each form of con-

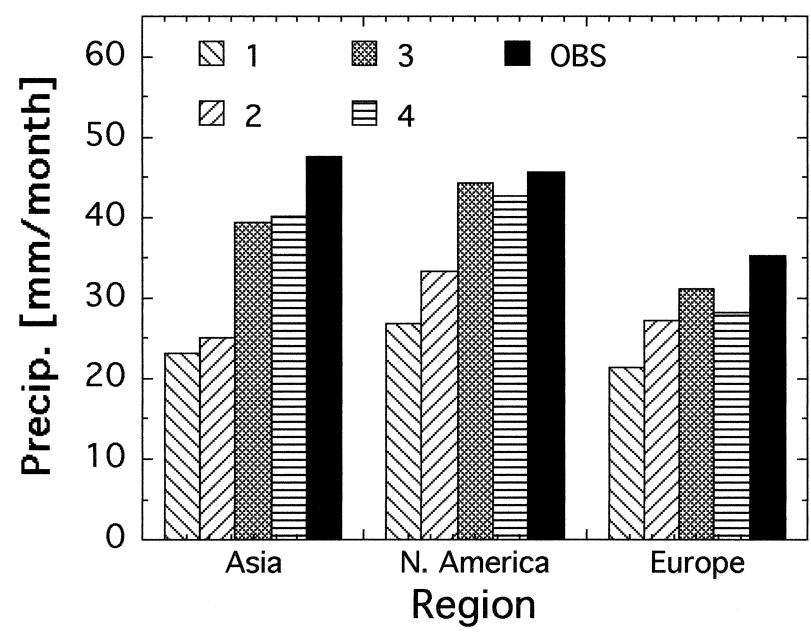

FIG. 2. Total precipitation for Jul 1986 from observations and simulations using four different cloud schemes. densed water. We narrowed possible thresholds to two alternatives by examining vertical profiles of $C_{L}$ and $C_{I}$ for four Arctic locations from a preliminary simulation that used the standard, relative humidity cloud diagnosis. We computed monthly average total cloud cover for different choices of $C_{L}$ and $C_{I}$ thresholds and specified cloud fraction. These were compared visually with monthly climatological cloud cover (Serreze et al. 1997) for the same locations to arrive at the two alternatives listed in Table 2 as schemes 3 and 4 .

Cloud diagnosis schemes 3 and 4 both gave better simulated precipitation than the relative humidity schemes (e.g., Fig. 2). Differences between schemes were greater in July (Table 3) than October (not shown). Further simulations used scheme 4 , as it gave an annual cycle of total cloud cover across the pan-Arctic that was more consistent with the observational climatology. The biggest change from reducing cloud cover compared to the original scheme was a two- to three-fold increase in surface solar radiation (Table 3 ), which warmed the surface and boundary layer by $0.5^{\circ}-2.5^{\circ} \mathrm{C}$. Net longwave radiation concurrently became more strongly upward, with about two-thirds of the change due to reduced downward longwave radiation from less cloud cover. More important were the increases in surface sensible and latent heat fluxes that not only warmed and moistened the boundary layer but also promoted substantial increases in convective precipitation, especially in the two largest continental watersheds. For each of the watersheds, increased surface evaporation was more than $70 \%$ of the magnitude of increased total precipitation, suggesting that increased precipitation resulted primarily from local water sources. Despite the greater precipitation, however, atmospheric profiles of relative humidity (not shown) had only slight reductions. The primary effects of avoiding excessive cloud cover were

TABLE 3. Cloud scheme 4 - cloud scheme 1 differences in surface fields for July 1986 simulations. Energy fluxes are given in $\mathrm{W} \mathrm{m}^{-2}$; precipitation is given in $\mathrm{mm}$ month $^{-1}$.

\begin{tabular}{lccc}
\hline \hline \multirow{2}{*}{\multicolumn{1}{c}{ Surface field }} & \multicolumn{2}{c}{ Continental analysis region } \\
\cline { 2 - 4 } & AAW & NAAW & EAW \\
\hline Absorbed shortwave radiation & 149.9 & 141.4 & 131.8 \\
Net longwave radiation into surface & -3.5 & -29.7 & -28.6 \\
Upward sensible heat flux & 20.6 & 22.3 & 18.6 \\
Upward latent heat flux & 22.7 & 15.8 & 11.6 \\
Nonconvective precipitation & 5.44 & 6.18 & 9.30 \\
Convective precipition & 20.25 & 12.01 & 6.88 \\
\hline
\end{tabular}



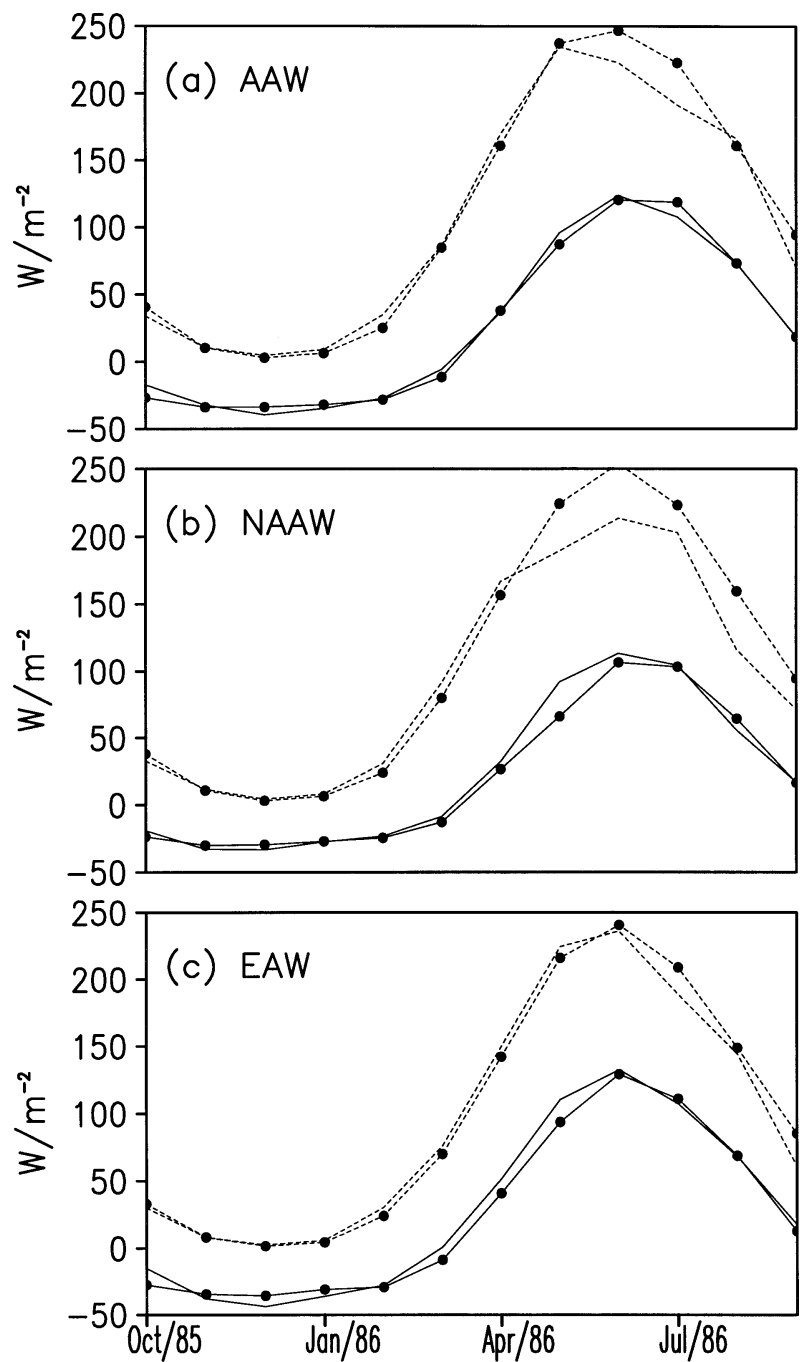

FIG. 3. Monthly average surface net radiation (solid) and shortwave downwelling flux (dashed) for each of the continental watersheds. Dots mark observations from the Polar Radiation Flux dataset; simulated output curves have no dots.

to increase energy transmission to the surface and strengthen the water cycle.

The primary reason for diagnosing cloud cover in the model is for its modulation of radiation. Figure 3 shows the monthly mean annual cycle of downwelling shortwave radiation and net total radiation at the surface from the model and the Polar Radiation Flux (PRF) dataset. Figure 3 and Table 3 confirm that the change in the cloud cover scheme improved surface insolation. However, insolation differences up to $35 \mathrm{~W} \mathrm{~m}^{-2}$ occur in summer for the two largest watersheds, suggesting further problems with cloud parameterization. The net cooling bias in winter months may be due in part to a cooling bias at high latitudes in the CCM2 radiation's computation of clear-sky downwelling longwave flux at the surface (Pinto and Curry 1997; Pinto et al. 1999). However, errors in simulating clouds can cause com-

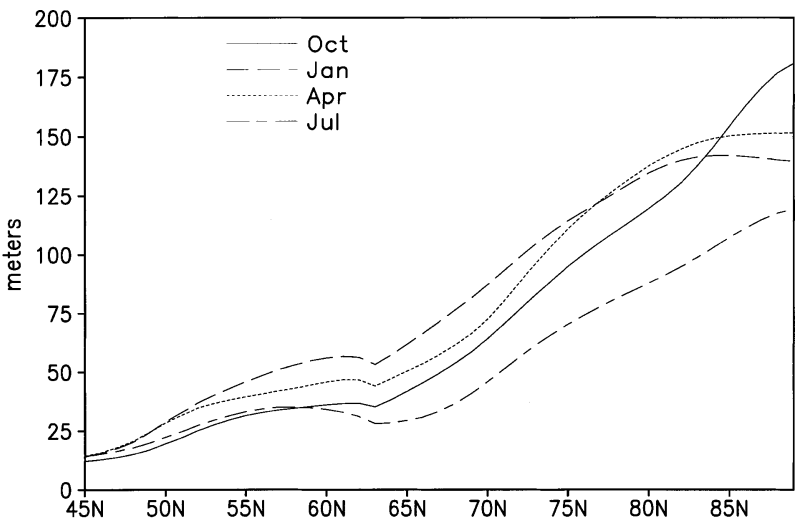

FIG. 4. Root-mean-square difference in 500-hPa geopotential height between simulation and NCEP-NCAR reanalysis, as a function of latitude for 4 months of the simulation period. Curves are monthly averages of daily rmsd.

parable or larger bias (Pinto et al. 1999) and can potentially reverse the sign of bias (Zhou and Cess 2000). In general, biases in Fig. 3 are similar in magnitude to radiation biases reported for other Arctic regional model simulations (Lynch et al. 1999; Rinke et al. 2000; Wu and Lynch 2000). However, there are differences among these runs in radiation datasets used for comparison, size of areas compared, and periods simulated that prevent more specific comparison.

\section{Calibrated model simulation}

In this section, we compare output from the full 1yr simulation (October 1985-September 1986) with data from the observational archives described in section 2 . We first analyze circulation and temperature fields, which provides the foundation for our ultimate goalanalyzing how well the model simulates water budgets in the pan-Arctic. We give special attention to the scaledependence of its accuracy, since we would like to know the smallest drainage areas for which the present model can simulate the water cycle reasonably accurately.

\section{a. Circulation}

As the simulation progresses during its first month, it steadily evolves away from the NCEP-NCAR reanalysis. For example, the daily, domain-averaged rootmean-square difference (rmsd) in 500-hPa geopotential height between the simulation and the concurrent reanalysis increases over a 2 -week period from zero (initial condition) to over $100 \mathrm{~m}$ (not shown). Most of the difference occurs within the circumpolar vortex (Fig. 4 ), where the influence of lateral boundary conditions on the model atmosphere is relatively weak. The differences over the first 2 weeks thus evolve in much the same way as error growth in numerical weather prediction. After 2 weeks, the 500-hPa geopotential height's rmsd meanders about $100 \mathrm{~m}$, showing no further growth. 

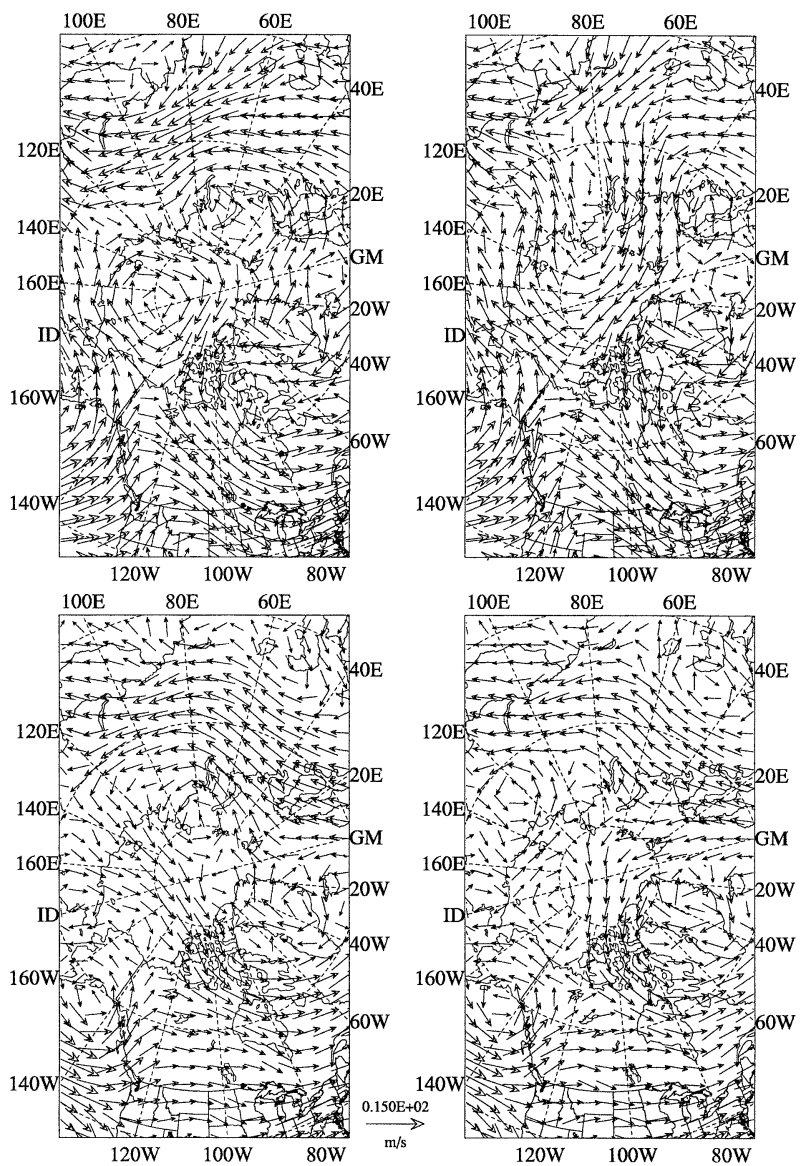

FIG. 5. Monthly average wind vectors at $850 \mathrm{hPa}$ for (top row) DJF and (bottom row) MAM in (left) the reanalysis and (right) the simulation. Reference vector between lower panels is $15 \mathrm{~m} \mathrm{~s}^{-1}$.

Differences between the simulation and the NNR remain fairly steady throughout the simulation (Fig. 4), indicating no drift in the model. The steadily increasing rmsd toward the North Pole is, in part, a consequence of a systematic difference, with the NNR having lower height values at high latitudes.

The systematic model-NNR difference in $500-\mathrm{hPa}$ geopotential heights implies that height gradients from the simulation domain's boundary to its center will be weaker, because the model's 500-hPa heights are forced to remain close to the NNR heights at the lateral boundaries. Consequently, model circulation should tend to be weaker in the interior, as the flow is expected to be quasigeostrophic. Figure 5 shows horizontal winds at $850 \mathrm{hPa}$ and is representative of differences and similarities between the simulated and NNR circulation patterns at all levels of the atmosphere. Also, the NNR circulation patterns are similar to $850-\mathrm{hPa}$ wind fields in corresponding analyses of the ECMWF (not shown), so model-NNR differences do not appear attributable to uncertainty in analysis schemes. Our primary interest is in the circulation over the land watersheds. In the December-January-February (DJF) average, the model and NNR both show a ridge-trough system over North America, northeastward flow over eastern Europe, a ridge in central Siberia, and a trough over western $\mathrm{Si}$ beria, although the model's Siberian ridge is more elongated and its Siberian trough not as wide as the NNR counterpart. In the March-April-May (MAM) average, the model and NNR again both show a ridge-trough system over North America and generally eastward flow across southern Siberia. However, the model does not produce the NNR's ridge-trough pattern over northern Europe and Siberia. Also, like other simulations that cover the entire Arctic Ocean (e.g., Rinke et al. 2000; Dethloff et al. 2001), the model has difficulty reproducing the strength and direction of the driving analysis' winds over the ocean. At least some of this difference may be due to sensitivity to the parameterization of the stable planetary boundary layer (Dethloff et al. 2001) as well as our simple ice model with no leads (Rinke et al. 1999). Overall, consistent with the systematic difference in $500-\mathrm{hPa}$ fields, the simulated $850-\mathrm{hPa}$ winds tend to be weaker than NNR winds.

As noted earlier, NNR circulation in the Arctic could be influenced by the climatology of its underlying forecast model and potentially depart from actual circulation. The HARA rawinsondes allow us to bypass influences of the NNR forecast model and perform direct comparison of the simulation with observations, though only at rawinsonde sites. We compared NNR, MM5, and HARA winds for 4 months in our simulation period: October 1985 and January, April, July 1986. We required the HARA stations used to report for at least $90 \%$ of the synoptic periods (0000 and 1200 UTC) in each month, on the assumption that such stations would give more reliable observations. Nearly complete time series also meant that these stations should have a persistent influence on the NNR data assimilation. On this basis, 34 to 39 stations emerged for use in each month, with 55 stations (Fig. 1) contributing in at least one month.

Gridded winds from the model and the NNR were interpolated to the candidate HARA sites (Fig. 1) using a Cressman scheme (Cressman 1959) with a $240-\mathrm{km}$ search radius. For both MM5 and NNR output in each month, we then computed the rmsd relative to HARA soundings for eastward $(u)$ and northward $(v)$ wind components. Figure 6 shows scatterplots of NNR rmsd versus MM5 rmsd. The two tend to be proportional to each other, with MM5's overall rmsd $\left(9.8 \mathrm{~m} \mathrm{~s}^{-1}\right)$ slightly smaller than the NNR's $\left(10.5 \mathrm{~m} \mathrm{~s}^{-1}\right)$. However, the difference is persistent, with MM5 rmsd smaller in over $70 \%$ of the cases. The net rmsd is also smaller in MM5 output for each component in each month except for January's $v$-component. MM5 rmsd is smaller than NNR rmsd most frequently in April and July (85\% of the comparisons) and least frequently in January (54\%). The model circulation thus matches these observations more closely than the NNR even though the NNR data assimilation cycle ingests observations every $6 \mathrm{~h}$. The 

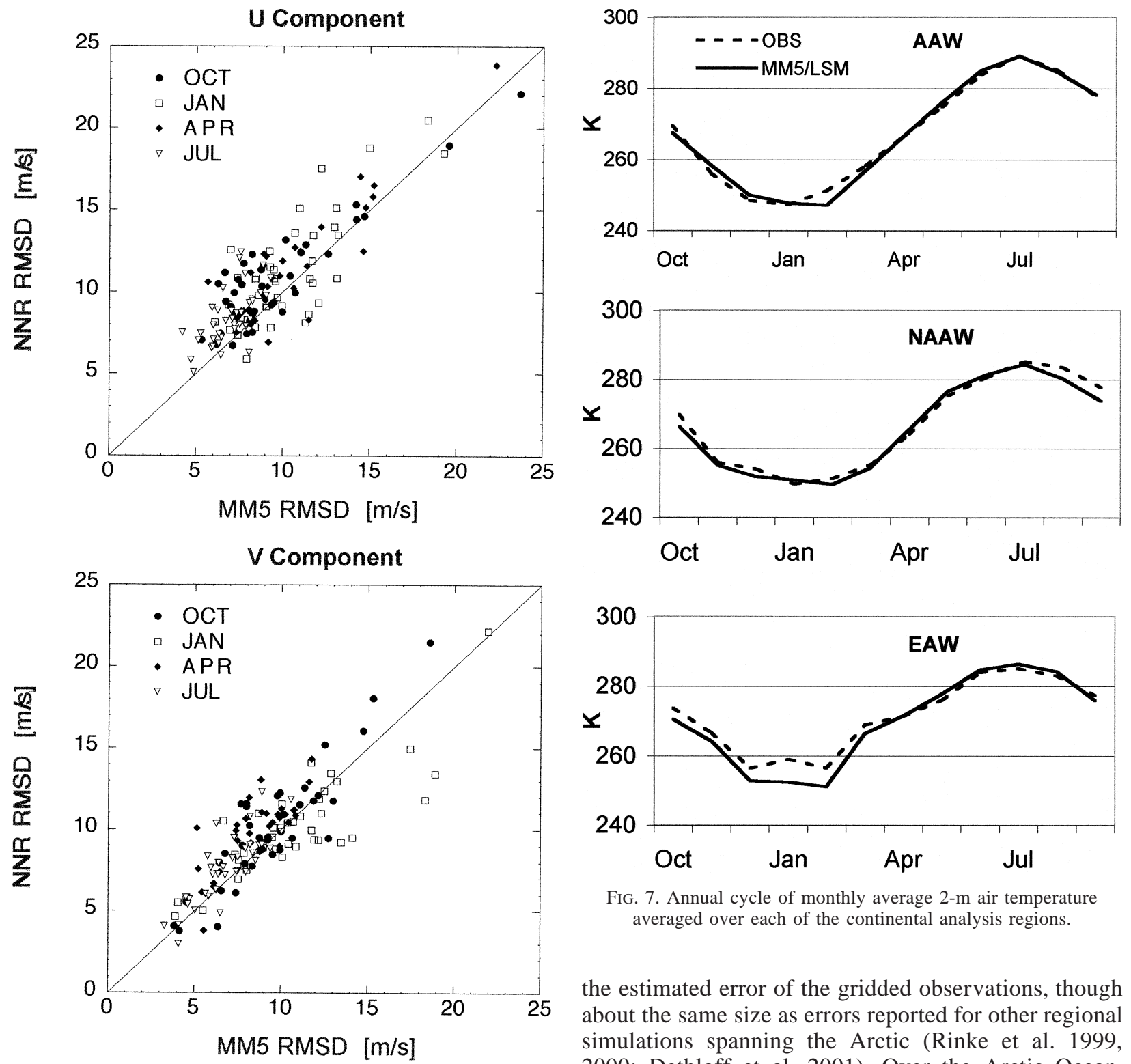

FIG. 6. Root-mean-square difference vs HARA of daily $850-\mathrm{hPa}$ (top) $u$ - and (bottom) $v$-components from the MM5 simulation and the NCEP-NCAR reanalysis.

comparison suggests that the model circulation may be better than the NNR's. Also, because the NNR winds tend to be stronger than the model's, the comparison suggests further that the model's weaker height depression in the central Arctic may be more realistic than the NNR's.

\section{b. Temperature}

Simulated 2-m air temperature shows absolute differences with the POLES dataset of less than $5^{\circ} \mathrm{C}$ for each month in each watershed except EAW in January and February (Fig. 7). These differences are larger than

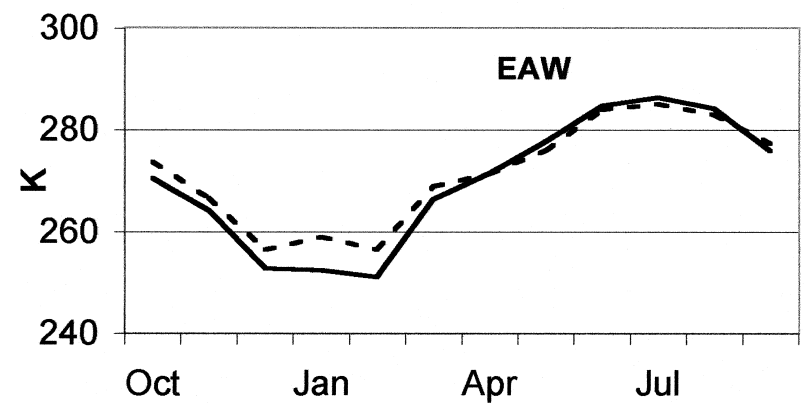

FIG. 7. Annual cycle of monthly average 2-m air temperature averaged over each of the continental analysis regions.

the estimated error of the gridded observations, though about the same size as errors reported for other regional simulations spanning the Arctic (Rinke et al. 1999, 2000; Dethloff et al. 2001). Over the Arctic Ocean, monthly differences are all less than $3^{\circ} \mathrm{C}$ (not shown). Simulated temperature profiles above the boundary layer also tend to be similar to profiles in the NNR and TOVS retrievals when averaged over each of the land regions for each season simulated (not shown).

The TOVS soundings give a bulk stratification parameter, defined as the difference in potential temperature between 900 and $1000 \mathrm{hPa}$ (Fig. 8). The model reproduces well the annual cycle of the bulk stratification parameter over the central Arctic Ocean. However, over the two largest land regions (AAW and NAAW), the simulated stratification parameter is always smaller than that given by TOVS soundings. Although the TOVS stratification parameter is derived from satellite retrievals, comparison with the same parameter from HARA soundings at several sites shows good agreement between TOVS and HARA values (not 

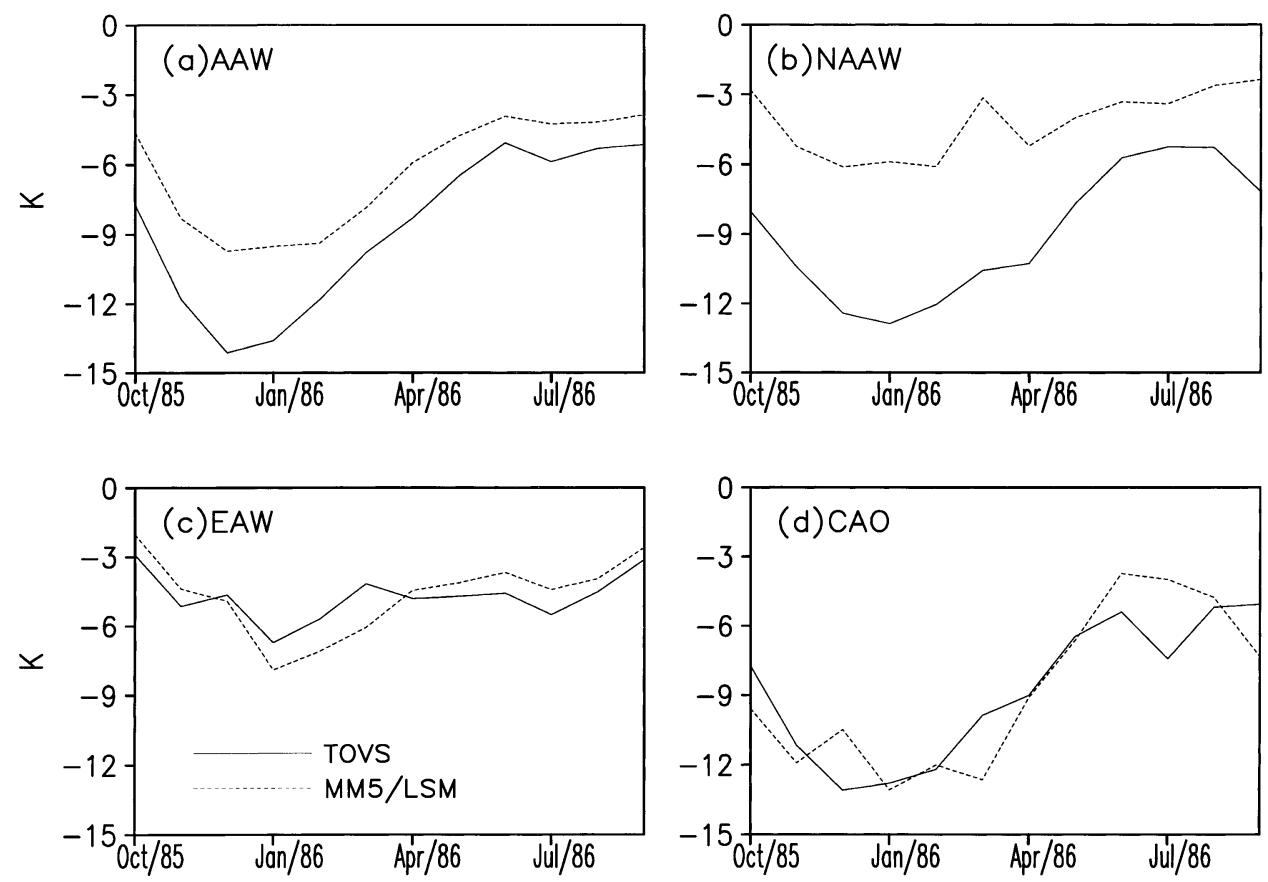

FIG. 8. Annual cycle of monthly average bulk stratification parameter for each of the analysis regions.

shown). The model does exhibit stronger stratification in winter than summer for both regions, but the amplitude of the annual cycle is weak. Thus, even though surface temperatures appear to be reproduced well, the model's planetary boundary layer does not have the strong, stable winter stratification seen in TOVS soundings. Overall, the model's land-area stratification parameter in winter is similar to that in a January simulation of the Arctic Region Climate System Model (ARCSyM) (Rinke et al. 2000). For the ARCSyM case, Rinke et al. (2000) suggest that its land planetary boundary layer is insufficiently stable because the boundary layer parameterization, designed for efficient vertical moisture transport in midlatitudes, cannot simulate highly stable boundary layers well. Our simulation uses a different parameterization, but it, too, was tested in a midlatitude environment (Zhang and Anthes 1982) and may also produce overly efficient transport that reduces excessively the vertical temperature differences of a stable boundary layer.

\section{c. Water budget}

Our primary goal for applying MM5 to the pan-Arctic is to simulate the high-latitude water cycle. TOVS and the NNR both give estimates of the atmosphere's precipitable water (PW) in the layer 300-900 hPa (Fig. 9). The model agrees fairly well with TOVS values in summer, but generally has too much precipitable water versus TOVS in winter. This positive bias occurs despite a slight tendency for cool bias in the NAAW and EAW watersheds (Fig. 7) and the less stable than observed, and hence cooler, boundary layer in the AAW and NAAW watersheds (Fig. 8). Recognizing shortcomings of NNR water vapor discussed earlier and the overall difficulty of measuring atmospheric water vapor well, the model's annual cycles of PW compare well with TOVS and NNR PW for each of the analysis regions.

The model's monthly precipitation for each of the analysis regions differs from CMAP precipitation by less than $1 \mathrm{~mm}$ day $^{-1}$ for all months except for AAW in August and EAW in July. Differences in most months are less than the estimated CMAP error (though presumably spatial averaging reduces CMAP error). The absolute differences are also similar but generally smaller than other simulated-observed precipitation differences (e.g., Christensen et al. 1998; Christensen and Kuhry 2000; Wu and Lynch 2000), though the regions averaged here represent much greater areas than those analyzed in these papers. We will see later that some of the better agreement is due to canceling errors in the spatial averaging. However, there is a clear, persistent summer dry bias in all three watersheds, especially the AAW. A prior simulation that used an unaltered LSM and allowed infiltration in frozen soil produced substantially more summer precipitation, including positive bias in some months. However, despite the added soil water, this run produced only about $20 \mathrm{~mm}$ more annual evaporation in each of the basins, so changes in local water sources do not appear to be large enough to explain the dry bias seen in Fig. 10. The cause for bias remains undetermined.

Precipitation leads to evapotranspiration and runoff. Evapotranspiration measurements for the pan-Arctic as 

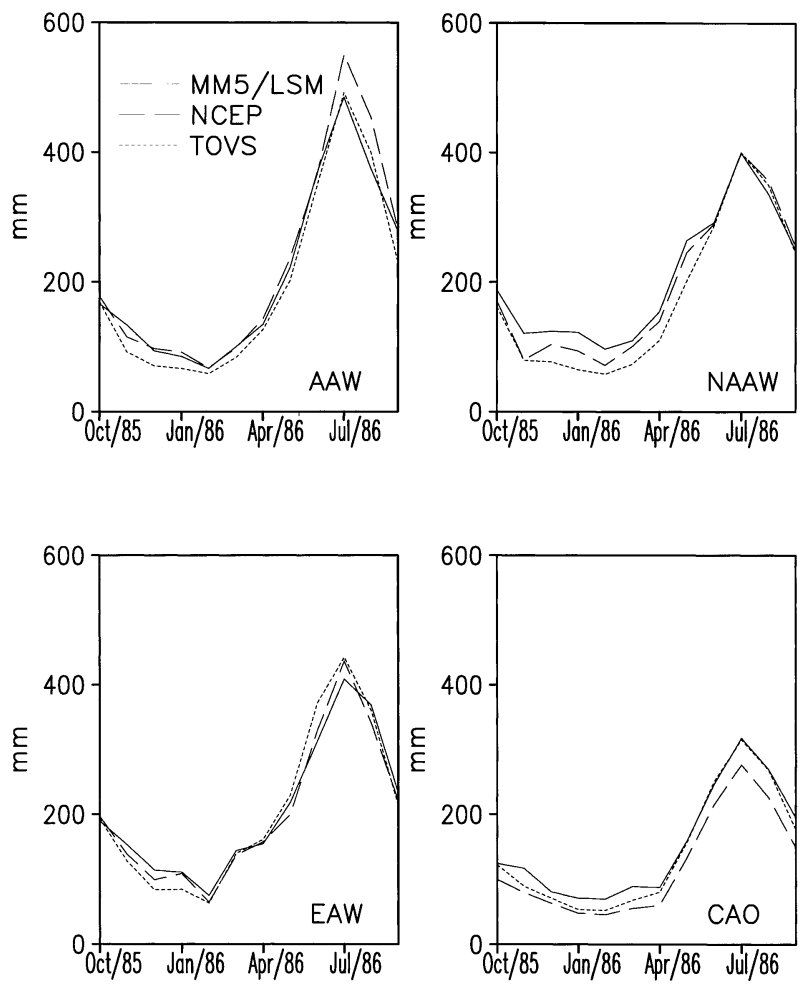

FIG. 9. Annual cycle of monthly average precipitable water in the layer $300-900 \mathrm{hPa}$ for each of the analysis regions.

a whole are not available, but the UNH-GRDC dataset gives an annual cycle of gridded, climatological runoff that we compare with our 1-yr simulation. As described earlier, we modified LSM infiltration for January and beyond to prohibit infiltration when temperatures in the soil model's upper $30 \mathrm{~cm}$ were below freezing. The simulation's maximum monthly runoff in each basin (Fig. 11) is similar to the UNH-GRDC climatology, indicating that the model is capable of producing a realistic springtime runoff surge. However, the model's spring maximum occurs $0.5-1$ month before the UNHGRDC climatology, and runoff decays more rapidly from its maximum than occurs in the observations.

The model's precipitation dry bias may contribute to this deficit, but only in the AAW watershed is the annual precipitation deficit large enough to match potentially the runoff deficit. Moreover, the largest precipitation deficit in each watershed occurs in July and August, well after runoff deficits appear. Of course, the estimated error in CMAP precipitation is large enough (approximately $40 \%$ ) that a substantial dry bias in CMAP precipitation could imply a model precipitation deficit large enough to account for the runoff deficit. CMAP precipitation is partly based on gauge observations, which may suffer from undercatch, especially in winter (e.g., Christensen et al. 1998; Christensen and Kuhry 2000 and references therein), implying a potentially larger precipitation than depicted in Fig. 10. Another possible contributor is excessive evapotranspiration. Although
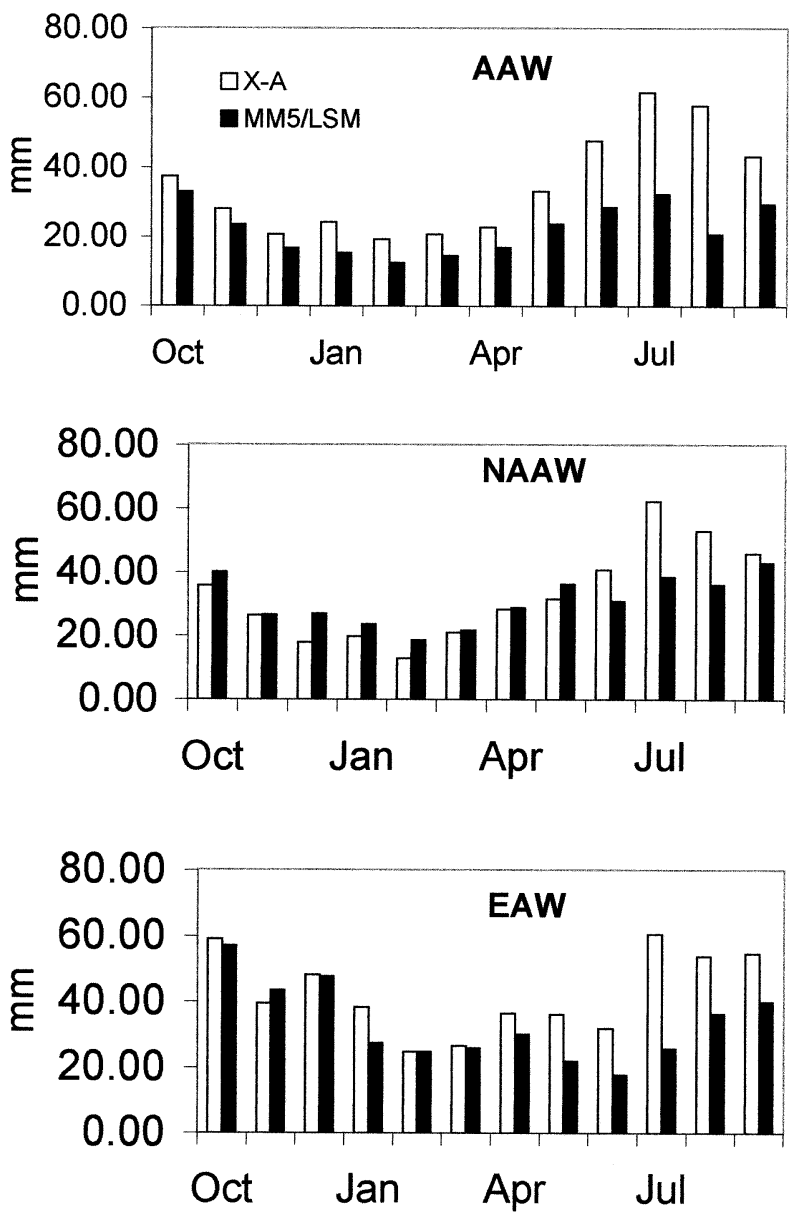

FIG. 10. Annual cycle of monthly accumulated precipitation for each of the continental analysis regions.

there is no observational database spanning the Arctic for evapotranspiration, Christensen et al. (1998) have found that evapotranspiration error in the HIRHAM Scandinavian simulation is primarily a function of surface temperature. This is due to the strong temperature dependence of saturation vapor pressure, which governs changes in near-surface vertical moisture gradients that prompt moisture flow. However, our simulation has a small net cool bias in surface temperature, implying a deficit in evapotranspiration if the same error behavior occurs in MM5. Finally, the slow decay of UNH-GRDC runoff is reminiscent of base flow evolution. The model does not include subterranean aquifers that could store water and release it as base flow contributing to the simulated annual cycle of runoff. The model's land-use dataset also does not include wetlands spread across parts of the Arctic (e.g., Bonan 1995). Evaluating the effects of such water reservoirs is a subject of ongoing work.

Of course, another reason for these differences could be simply that the model is simulating just $1 \mathrm{yr}$, whereas the UNH-GRDC data represent a multiyear average. However, long-term discharge records for the $\mathrm{Ob}$, Lena, 

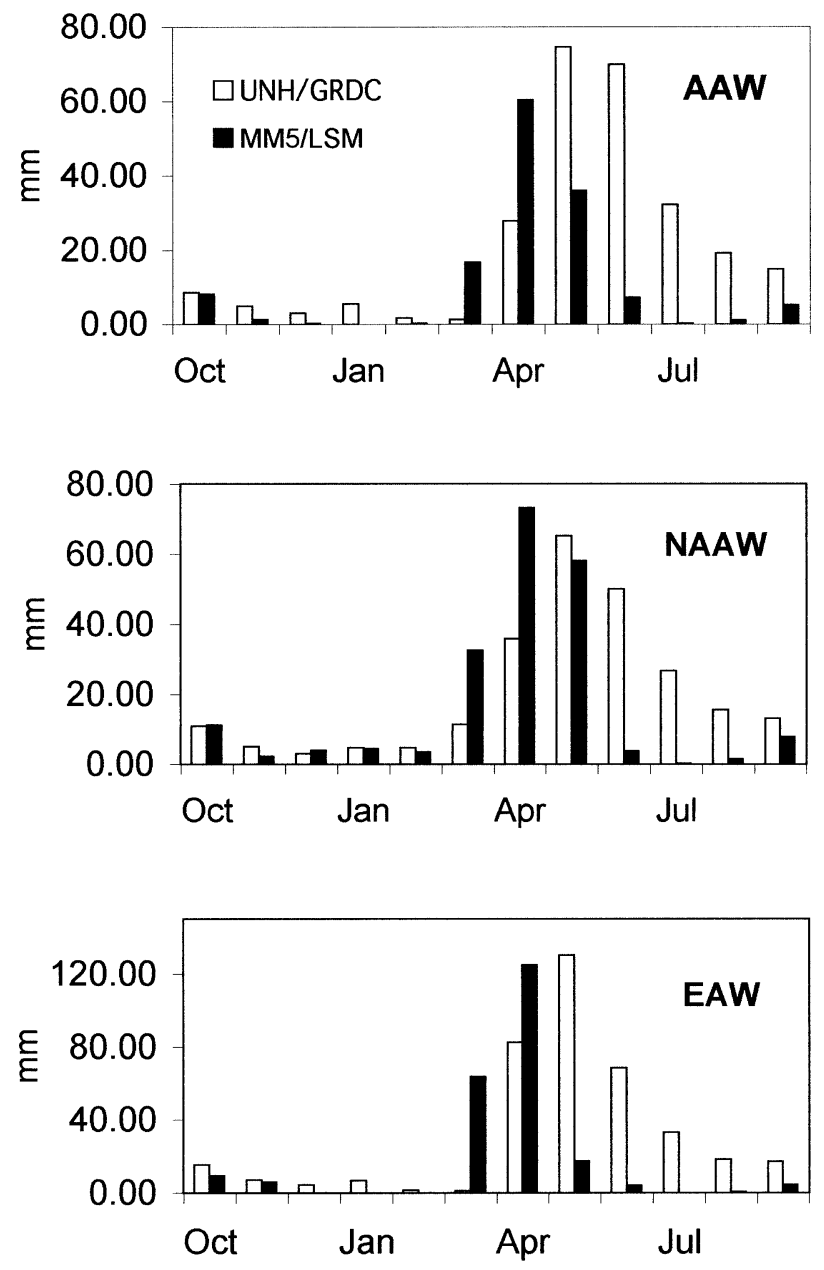

FIG. 11. Annual cycle of observation-based climatological runoff (UNH-GRDC) and simulated runoff for the year simulated (Oct 1985-Sep 1986) for each of the continental analysis regions. Note different scales on panels.

Yenesei, and Kolyma basins (Vorosmarty et al. 1996, 1998) show that the total discharge from these basins for October 1985-September 1986 was within 1\% of the long-term October-September annual discharge. Similar computations for the MacKenzie and Nelson basins show that their total discharge for the simulation period was only $5 \%$ greater than long-term averages. Monthly discharge values also indicated no significant departure from climatology in the timing of the annual cycle's maximum discharge. The UNH-GRDC runoff climatology is thus representative of the year we simulated. Overall, the model shows that it is capable of rendering realistic runoff, though its quantitative accuracy for the year simulated needs further improvement.

\section{d. Scale-dependence of errors}

The model has been applied with an eye toward panArctic hydrologic cycle simulation. Land surface hy- drology is organized by river basins of varying size. Model output will have errors that prevent accurate water-cycle simulation for smaller basins, but a portion of the error may be random and thus much smaller when averaged over areas large enough for random errors to cancel. Since the model reproduces fairly well several observed fields for our simulation period when averaged over continental domains, one would like to know the smallest basin sizes for which the present model might yield reasonable simulation of the coupled land-atmosphere hydrologic cycle. For example, Fekete et al. (2001) and Vorosmarty et al. (2000a,b) indicate that a $0.5^{\circ}$ digital stream network and runoff grid resolves hydrologic evolution best for basins exceeding 25000 $\mathrm{km}^{2}$.

We have computed a dependence of simulation error on averaging domain size for precipitation and 2-m temperature. Precipitation is of course a water source for a basin's terrestrial hydrology. Evapotranspiration from the surface is a loss to the terrestrial water budget and, as discussed above, evapotranspiration error can be strongly dependent on surface air temperature error (Christensen et al. 1998). Assuming such temperature control in our model, analyses of the scale-dependence of temperature as well as precipitation errors are relevant to assessing the model's capability for regional hydrology simulation.

We assume that root-mean-square differences for simulated-CMAP precipitation and simulated-POLES 2-m temperature are entirely model error. We then compute error in both fields for simulated and observed values averaged over progressively smaller regions, using North American and Asian domains (Fig. 1) that we subdivide repeatedly to the limit of model grid spacing. We combine errors from regions the same size by computing the root-mean-square (rms) error. This procedure is done for each month of the year, after which we compute an annual rms error by taking the square root of monthly average error variance. The pan-Arctic is characterized by important variations in hydrologic processes during the annual cycle (e.g., freeze/thaw). Thus, our metric for assessment is the amplitude of a field's annual cycle averaged over the domain in question (North American or Asian). An acceptable model must have at least marginal ability to resolve the annual cycle of hydrologic processes; otherwise it is missing fundamental behavior of the water cycle. Other, more stringent metrics of course could be used, such as model error versus presumed measurement and data processing error. We view the choice adopted here as a minimal requirement.

The slopes of the curves in Fig. 12 indicate the scales contributing to model error. If the curve decreases rapidly with increasing spatial scale, then smaller scales make large contributors to simulation error. If, on the other hand, the curve is flat with increasing spatial scale, then the largest scales dominate the error. Thus, temperature error (Fig. 12) results primarily from an overall 


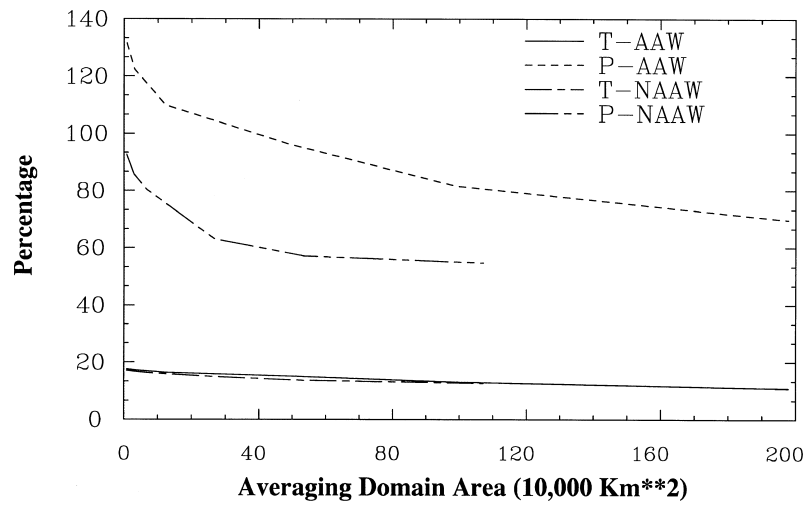

FIG. 12. The percentage ratio $\mathrm{rmsd} /($ amplitude of annual cycle) vs averaging domain area.

regional bias for both watersheds, whereas precipitation error has important contribution from many scales, including the largest and smallest resolved. On the basis of our metric, surface temperature error is acceptably small for all spatial scales, but precipitation error only marginally acceptable, if that, at the largest scales.

Consideration of absolute error implied by Figs. 7, 11, and 12 provides further perspective. If we assume that the ratio (evapotranspiration error)/(temperature error) found by Christensen et al. (1998) applies here, then annual evapotranspiration error is about $20 \mathrm{~mm}$ month ${ }^{-1}$ in both basins. Annual precipitation error ranges 14-28 mm month ${ }^{-1}$. By this estimate, each has error comparable to the annual average runoff in the AAW and NAAW basins, suggesting that further improvement in both temperature and precipitation simulation is needed to simulate annual runoff well.

\section{Summary and discussion}

We have performed a 1-yr RCM simulation for the pan-Arctic to assess the quantitative performance of a version of PSU-NCAR MM5 being developed for studying the region's land-atmosphere hydrologic cycle. Development has included coupling MM5 to a simple thermodynamic sea ice model and Bonan's (1996) LSM Short test simulations with the model revealed biases in precipitation due to excessive cloud cover. We corrected the problem by replacing the model's standard cloud diagnosis based on relative humidity with one based on the model's predicted cloud water and cloud ice fields. The new scheme gives cloud in a model layer when either cloud liquid water or cloud ice water exceed thresholds that we calibrated to yield cloud cover in approximate agreement with climatology.

We assessed performance of the 1-yr simulation using a number of recently released datasets based on direct observations, satellite retrievals, and atmospheric reanalyses, focusing on fields relevant to the hydrologic cycle: atmospheric circulation, temperature, surface radiation fluxes, precipitation, and runoff. Most attention was given to model performance over continental-average watersheds draining into the Arctic Ocean, for which the model simulates fairly well annual average surface air temperature (bias $<2{ }^{\circ} \mathrm{C}$ ) and precipitation (bias $<0.5 \mathrm{~mm} \mathrm{day}^{-1}$ ).

Comparison of $850-\mathrm{hPa}$ horizontal winds with HARA rawinsonde soundings from sites with frequent observations shows that rms difference versus soundings ( 9.8 $\left.\mathrm{m} \mathrm{s}^{-1}\right)$ is less than the reanalysis rms difference versus soundings $\left(10.5 \mathrm{~m} \mathrm{~s}^{-1}\right)$. This result further justifies a decision made, when developing the model, to avoid placing any of the model's lateral boundaries over the poorly observed Arctic Ocean, even though the resulting domain size (Fig. 1) was rather large. Although this result may be somewhat satisfying from the perspective of the RCM assessment, it is nonetheless perplexing, because the reanalysis should be governed by these rawinsondes where they occur in the Arctic. The result raises the question, unaddressed here, as to whether or not the reanalysis quality-control scheme may have rejected these observations. Another possibility is that the reanalysis forecast model drifts so strongly toward its own climatology in the Arctic that the few available rawinsondes are insufficient to constrain it. For example, the spectral snow problem (Ebisuzaki et al. 1997) produces spurious heating that may degrade momentum fields in the reanalysis forecast model.

The model produces a spring runoff surge for the continental watersheds that is comparable in magnitude to observations, but annual runoff is less than observed. Precipitation error contributes to this bias, but other factors also appear to be important. Comparison of simulated and observed runoff evolution (Fig. 11) suggests that aquifer modeling may be necessary to reproduce the magnitude and timing of runoff. Another reason why the model has less runoff may be that it is missing Arctic wetland areas not contained in the standard MM5 land surface description. Understanding the influence of these wetlands is a subject of current study.

Our intent in developing this model is to provide a coherent framework for studying the coupled land-atmosphere-ocean hydrologic cycle across high northern latitudes, recently highlighted as a critical and strategic need for Arctic science (Vorosmarty et al. 2001). This analysis has highlighted several issues that pan-Arctic synthesis studies of the water cycle would immediately confront. Our analysis of precipitation and temperature errors shows that the model simulates these fields with monthly accuracy in most (but not all) months that approach estimates of observational accuracy. Other models cited yield similar behavior. However, further analysis of our simulation suggests that such accuracy may only be acceptable, at best, for the largest basins, suggesting that improvement is needed not only in simulation but also in the variety, areal extent, density, and accuracy of observational databases used for model assessment and improvement.

Finally, despite these emerging challenges, we be- 
lieve that only by using a mass- and energy-conserving approach over the full pan-Arctic domain can we begin to understand the highly complex interconnections between the region's land, atmosphere, and ocean. An objective validation using such an approach with retrospective datasets is necessary to identify critical research directions and ultimately permit analysis of issues such as future global warming's impact on the region's water and energy cycles. We have attempted to provide steps toward that validation here.

Acknowledgments. This work was supported by U.S. Department of Energy Grant DEFG0296ER61473. Mr. D. Flory performed the LSM-MM5 coupling. Dr. Z. Otles assisted with early simulations. We thank Dr. Jeff Key for kindly providing us with surface radiation fluxes from the Polar Radiation Flux Project and the two anonymous reviewers for questions and comments that improved this paper. TOVS Pathfinder Path-P Daily Arctic Gridded Atmospheric Parameters and HARA rawinsonde data were obtained from the EOSDIS NSIDC Distributed Active Archive Center (NSIDC DAAC) at the University of Colorado, Boulder. Data from the POLES program were obtained from the Polar Science Center of the University of Washington. The computer support used in this study was provided by the National Center for Atmospheric Research sponsored by the National Science Foundation.

\section{REFERENCES}

Anisimov, O. A., and F. E. Nelson, 1996: Permafrost distribution in the Northern Hemisphere under scenarios of climatic change. Global Planet. Change, 14, 59-72.

— - N. I. Shiklomanov, and F. E. Nelson, 1997: Global warming and active-layer thickness: Results from transient general circulation models. Global Planet. Change, 15, 61-77.

Arakawa, A., and V. R. Lamb, 1979: Energy and potential energy conserving scheme for the shallow-water equations. Preprints, Fourth Conf. on Numerical Weather Prediction, Silver Spring, MD, Amer. Meteor. Soc., 201-208.

Bailey, D. A., A. H. Lynch, and K. Hedstrom, 1997: Impact of ocean circulation on regional polar climate simulations using the Arctic Regional Climate System Model. Ann. Glaciol., 25, 203-207.

Battisti, D. S., D. L. Williamson, and R. E. Moritz, 1992: Simulation of the arctic climatology with the NCAR CCM-2. Preprints, Third Conf. on Polar Meteorology and Oceanography, Portland, OR, Amer. Meteor. Soc., 133-136.

Bonan, G. B., 1995: Sensitivity of a GCM simulation to inclusion of inland water surfaces. J. Climate, 8, 2691-2704.

__ 1996: A land surface model (LSM version 1.0) for ecological, hydrological, and atmospheric studies: Technical description and user's guide. NCAR Tech. Note NCAR/TN-417+STR, 150 pp. [Available from National Center for Atmospheric Research, P.O. Box 3000, Boulder, CO 80305.]

Briegleb, B. P., 1992: Delta-Eddington approximation for solar radiation in the NCAR Community Climate Model. J. Geophys. Res., 97, 7603-7612.

Chedin, A., N. A. Scott, C. Wahiche, and P. Moulinier, 1985: The Improved Initialization Inversion method: A high resolution physical method for temperature retrievals from satellites of the TIROS-N series. J. Climate Appl. Meteor., 24, 128-143.

Chen, B., D. H. Bromwich, K. M. Hines, and X. Pan, 1995: Simu- lations of the 1979-1988 polar climates by global climate models. Ann. Glaciol., 21, 83-90.

Christensen, J. H., and P. Kuhry, 2000: High-resolution regional climate model validation and permafrost simulation for the East European Russian Arctic. J. Geophys. Res., 105, 29 647-29 658.

Christensen, O. B., J. H. Christensen, B. Machenauer, and M. Botzet, 1998: Very high resolution regional climate simulations over Scandinavia-Present climate. J. Climate, 11, 3204-3229.

Cressman, G. P., 1959: An operational objective analysis system. Mon. Wea. Rev., 87, 367-374.

Curry, J. A., and E. E. Ebert, 1992: Annual cycle of radiation fluxes over the Arctic Ocean: Sensitivity to cloud optical properties. $J$. Climate, 5, 1267-1280.

_- W. B. Rossow, D. Randall, and J. L. Schramm, 1996: Overview of Arctic cloud and radiation characteristics. J. Climate, 9, 17311764.

Dethloff, K., A. Rinke, R. Lehmann, J. H. Christenen, M. Botzet, and B. Machenhauer, 1996: A regional climate model of the Arctic atmosphere. J. Geophys. Res., 101, 23 401-23 422.

__, C. Abegg, A. Rinke, I. Hebestadt, and V. F. Romanov, 2001: Sensitivity of Arctic climate simulations to different boundary-

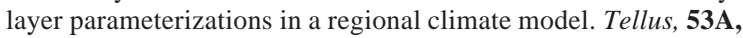
$1-26$.

Dudhia, J., 1989: Numerical study of convection observed during winter monsoon experiment using a mesoscale two-dimensional model. J. Atmos. Sci., 46, 3077-3107.

Ebisuzaki, W., M. Chelliah, and R. Kistler, 1997: NCEP/NCAR Reanalysis: Caveats. Proc. First WCRP Int. Conf. on Reanalyses, Silver Spring, MD, World Climate Research Program, WCRP104, WMO/TD-876, 81-84.

Fekete, B. M., C. J. Vörösmarty, and W. Grabs, 1999: Global, composite runoff fields based on observed river discharge and simulated water balances. WMO-Global Runoff Data Centre Rep. 22, 100 pp. [Available online at http://www.grdc.sr.unh.edu/ html/paper/ReportUS.pdf.]

,$- \ldots$, and R. B. Lammers, 2001: Scaling gridded river networks for macroscale hydrology: Development, analysis, and control of error. Water Resour. Res., 37, 1955-1967.

Francis, J. A., 1994: Improvement to TOVS retrievals over sea ice and applications to estimating Arctic energy fluxes. J. Geophys. Res., 99, 10 395-10 408.

Grell, A. G., 1993: Prognostic evaluation of assumptions used by cumulus parameterizations. Mon. Wea. Rev., 121, 764-787.

__, Y.-H. Kuo, and R. Pasch, 1991: Semi-prognostic tests of cumulus parameterization schemes in the middle latitudes. Mon. Wea. Rev., 119, 5-31.

—, H. Dudhia, and D. S. Stanfler, 1994: A description of the fifthgeneration Penn State-NCAR mesoscale model (MM5). NCAR Tech. Note NCAR/TN-398+STR, 122 pp. [Available from National Center for Atmospheric Research, P.O. Box 3000, Boulder, CO 80305.]

Hines, K. M., D. H. Bromwich, and T. R. Parish, 1995: A mesoscale modeling study of the atmospheric circulation of high southern latitudes. Mon. Wea. Rev., 123, 1146-1165.

- _ - and R. I. Cullather, 1997a: Evaluating moist physics for Antarctic mesoscale simulations. Ann. Glaciol., 25, 282-286.

$\ldots$ _ _ - and Z. Liu, 1997b: Combined global climate model and mesoscale: Model simulations of Antarctic climate. J. Geophys. Res., 102, 13 747-13 760.

Jurrens, R., 1999: Validation of surface fluxes in climate simulations of the Arctic with the regional model REMO. Tellus, 51A, 698709.

Kahl, J. D., M. C. Serreze, S. Shiotani, S. M. Skony, and R. C. Schnell, 1992: In situ meteorological sounding archives for Arctic studies. Bull. Amer. Meteor. Soc., 73, 1824-1830.

Kalnay, E., and Coauthors, 1996: The NCEP/NCAR 40-Year Reanalysis Project. Bull. Amer. Meteor. Soc., 77, 437-471.

Kattenberg, A., and Coauthors, 1995: Climate models-Projections of future climate. Climate Change 1995: The Science of Climate 
Change, J. T. Houghton et al., Eds., Cambridge University Press, 289-357.

Key, J., D. Slayback, C. Xu, and A. Schweiger, 1999: New climatologies of polar clouds and radiation based on the ISCCP ' $D$ ' products. Preprints, Fifth Conf. on Polar Meteorology and Oceanography, Dallas, TX, Amer. Meteor. Soc., 227-232.

Lynch, A. H., W. L. Chapman, J. E. Walsh, and G. Weller, 1995: Development of a regional climate model of the western Arctic. J. Climate, 8, 1555-1570.

—, G. B. Bonan, F. S. Chapin III, and W. Wu, 1999: The impact of tundra ecosystems on the surface energy budget of Alaska. J. Geophys. Res., 104, 6647-6666.

Mitchell, J. F. B., S. Manabe, V. Meleshko, and T. Tokioka, 1990: Equilibrium climate change-and its implications for the future. Climate Change: The IPCC Scientific Assessment, J. T. Houghton, G. J. Jenkins, and J. J. Ephraums, Eds., Cambridge University Press, $131-172$.

Mysak, L. A., 1995: Interdecadal variability in the Arctic and northern North Atlantic: Observations and models. Preprints, Fourth Conf. on Polar Meteorology and Oceanography, Dallas, TX, Amer. Meteor. Soc., (J9)26-(J9)27.

National Snow and Ice Data Center, 1999: TOVS Pathfinder Path-P daily Arctic gridded atmospheric parameters. EOSDIS NSIDC Distributed Active Archive Center, University of Colorado, Boulder, Boulder, CO. [Digital data available from nsidc@kryos.colorado.edu.]

Oechel, W. C., G. L. Vourlitis, S. J. Hastings, R. C. Zulueta, L. Hinzman, and D. Kane, 2000: Acclimation of ecosystem $\mathrm{CO}_{2}$ exchange in the Alaskan Arctic in response to decadal climate warming. Nature, 406, 978-981.

Overland, J. E., J. M. Adams, and N. A. Bond, 1997: Regional variation of winter temperatures in the Arctic. J. Climate, 10, 821837.

Pinto, J. O., and J. A. Curry, 1997: Role of radiative transfer in the modeled mesoscale development of summertime arctic stratus. J. Geophys. Res., 102, 13 861-13 872.

_, _ , and A. H. Lynch, 1999: Modeling clouds and radiation for the November 1997 period of SHEBA using a column climate model. J. Geophys. Res., 104, 6661-6678.

Randall, D., and Coauthors, 1998: Status and outlook for large-scale modeling of atmosphere-ice-ocean interactions in the Arctic. Bull. Amer. Meteor. Soc., 79, 197-219.

Rigor, I. G., R. L. Colony, and S. Martin, 2000: Variations in surface air temperature observations in the Arctic 1979-97. J. Climate, 13, 896-914

Rinke, A., K. Dethloff, and J. H. Christensen, 1999: Arctic winter climate and its interannual variations simulated by a regional climate model. J. Geophys. Res., 104, 19 027-19038.

— , A. H. Lynch, and K. Dethloff, 2000: Intercomparison of Arctic regional climate simulations: Case studies of January and June 1990. J. Geophys. Res., 105, 29 669-29 683.

Rossow, W. B., L. C. Garder, P.-J. Lu, and A. Walker, 1988: International Cloud Climatology Project (ISCCP) documentation of cloud data. WMO Tech Doc. 266, 78 pp. [Available from World Meteorological Organization, CP 2300-1211 Geneva 2, Switzerland.]

_ C. L. Brest, and M. D. Roiter, 1996: International Satellite
Cloud Climatology Project (ISCCP) new radiance calibrations WMO Tech. Doc. 736, 76 pp. [Available from World Meteorological Organization, CP 2300-1211 Geneva 2, Switzerland.]

Schweiger, A. J., R. W. Lindsay, J. R. Key, and J. A. Francis, 1999 Arctic clouds in multiyear satellite data sets. Geophys. Res. Lett., 26, 1845-1848.

Serreze, M. C., J. A. Maslanik, and J. Key, 1997: Atmospheric and sea ice characteristics of the Arctic Ocean and the SHEBA field region of the Beaufort Sea. NSIDC Special Rep. 4, 219 pp. [Available from National Snow and Ice Data Center, University of Colorado, Boulder, Boulder, CO 80309-0449.]

Tao, X., J. E. Walsh, and W. L. Chapman, 1996: An assessment of global climate model simulations of Arctic air temperatures. $J$. Climate, 9, 1060-1076.

Vörösmarty, C. J., B. Fekete, and B. A. Tucker, 1996: River Discharge Database, version 1.0 (RivDIS v1.0), volumes 0 through 6. A contribution to IHP-V Theme 1, Technical Documents in Hydrology Series, 1157 pp. [Available from UNESCO, 75352 Paris 07 SP, France.]

$\ldots, \ldots$, and —_, 1998: River Discharge Database, version 1.1 (RivDIS v1.0 supplement). 1157 pp. [Available from the Institute for the Study of Earth, Oceans, and Space, University of New Hampshire, Durham, NH 03824-3525, and online at http:// www.rivdis.sr.unh.edu/.]

,$- \ldots$ M. Meybeck, and R. Lammers, 2000a: A simulated topological network representing the global system of rivers at 30minute spatial resolution (STN-30). Global Biogeochem. Cycles, 14, 599-621

,,--- , and,$- 2000 \mathrm{~b}$ : Geomorphometric attributes of the global system of rivers at 30-minute spatial resolution (STN30). J. Hydrol., 237, 17-39.

—_ and Coauthors, 2001: The hydrologic cycle and its role in Arctic and global environmental change: A rationale and strategy for synthesis study. Arctic Research Consortium of the U.S. Rep., Fairbanks, AK, $84 \mathrm{pp}$

Walsh, J. E., and R. G. Crane, 1992: A comparison of GCM simulations of arctic climate. Geophys. Res. Lett., 19, 29-32.

_ , A. Lynch, and W. Chapman, 1993: A regional model for studies of atmosphere-ice-ocean interaction in the western Arctic. Meteor. Atmos. Phys., 51, 179-194.

— V. Kattsov, D. Portis, and V. Meleshko, 1998: Arctic precipitation and evaporation: Model results and observational estimates. J. Climate, 11, 72-87.

Williamson, D. L., and P. J. Rasch, 1994: Water vapor transport in the NCAR CCM2. Tellus, 46, 34-51.

Wu, W., and A. H. Lynch, 2000: Response of the seasonal carbon cycle in high latitudes to climate anomalies. J. Geophys. Res. 105, 22 897-22 908.

Xie, P., and P. A. Arkin, 1997: Global precipitation: A 17-year monthly analysis based on gauge observations, satellite estimates, and numerical model outputs. Bull. Amer. Meteor. Soc., 78, 25392558.

Zhang, D.-L., and R. A. Anthes, 1982: A high-resolution model of the planetary boundary layer-Sensitivity tests and comparisons with SESAME-79 data. J. Appl. Meteor., 21, 1594-1609.

Zhou, Y. P., and R. D. Cess, 2000: Validation of longwave atmospheric radiation models using Atmospheric Radiation Measurement data. J. Geophys. Res., 105, 29 703-29 716. 